\title{
Venovenous ECMO in Severe ARDS
}

\author{
Fouzia Douirek ${ }^{1}$, Nada Samkaoui ${ }^{2}$, Manal Rhezali ${ }^{1}$, Mohamed Abdenasser Samkaoui $^{1}$ \\ ${ }^{1}$ Polyvalent Intensive Care Unit, Arrazi Hospital, Mohammed VI ${ }^{\text {th }}$ University Centre, Cadi Ayyad University, Marrakech, Morocco \\ ${ }^{2}$ Medical University of Warsaw, Warszawa, Poland \\ Email: fouzia-douirek@hotmail.fr
}

How to cite this paper: Douirek, F., Samkaoui, N., Rhezali, M. and Samkaoui, M.A. (2021) Venovenous ECMO in Severe ARDS. International Journal of Clinical Medicine, 12, 273-278.

https://doi.org/10.4236/ijcm.2021.127024

Received: May 2, 2021

Accepted: July 4, 2021

Published: July 7, 2021

Copyright $\odot 2021$ by author(s) and Scientific Research Publishing Inc. This work is licensed under the Creative Commons Attribution International License (CC BY 4.0).

http://creativecommons.org/licenses/by/4.0/

\begin{abstract}
The Veno-venous Extra Corporeal Membrane Oxygenation (ECMO) indications and usage has strikingly progressed over the last years; especially with the COVID 19 pandemic, it has become an essential tool in the care of adults and children with severe pulmonary dysfunction refractory to conventional management. In this article, we will provide a review of ECMO development, clinical indications, patients' management, options and cannulations techniques, complications, outcomes, and the appropriate strategy of organ management while on ECMO.
\end{abstract}

\section{Keywords}

Critical Care, Extracorporeal Membrane Oxygenation, Intensive Care Units, Respiratory Distress Syndrome, Respiratory Failure, Review, Ventilation Artificial

\section{Introduction}

Acute Respiratory Distress Syndrome (ARDS) is a severe pulmonary and systemic disease with a high mortality rate, especially in the most severe forms with refractory hypoxemia. Despite the use of exceptional adjunctive therapies, mortality exceeds $60 \%$ [1]. This has motivated some teams to use an extracorporeal circuit combining a centrifugal pump and a membrane oxygenator, providing total pulmonary assistance allowing blood oxygenation and $\mathrm{CO}_{2}$ extraction, this technique is also called ECMO for Extra Corporeal Membrane Oxygenation [2]. This review is a practical summary of VV ECMO.

\section{ARDS Definition}

The most common indication for ECMO in respiratory failure is severe ARDS, which is basically defined by the presence of bilateral infiltrates on chest imaging 
within 7 days of an inciting event and impaired oxygenation $\left(\mathrm{PaO}_{2} / \mathrm{FIO}_{2}\right.$ ratio $<$ $100 \mathrm{~mm} \mathrm{Hg}$ while receiving positive-pressure ventilation), which is not fully explained by cardiogenic pulmonary edema [3].

The acute respiratory distress syndrome (ARDS) was defined in 1994 by the American-European Consensus Conference (AECC); since then, issues regarding the reliability and validity of this definition have emerged. Using a consensus process, a panel of experts convened in 2011 and developed the Berlin Definition, composed of 3 mutually exclusive categories of ARDS based on degree of hypoxemia: mild $\left(\mathrm{PaO}_{2} / \mathrm{FIO}_{2} \leq 300 \mathrm{~mm} \mathrm{Hg}\right)$, moderate $\left(\mathrm{PaO}_{2} / \mathrm{FIO}_{2} \leq 200 \mathrm{~mm}\right.$ $\mathrm{Hg})$, and severe $\left(\mathrm{PaO}_{2} / \mathrm{FIO}_{2} \leq 100 \mathrm{~mm} \mathrm{Hg}\right)[3]$.

ARDS is an acute, diffuse, inflammatory lung injury that leads to increased pulmonary vascular permeability, pulmonary compliance reduction, ventilation/perfusion mismatch, consolidation and alveolar collapses, surfactant defect and systemic repercussions via inflammatory cytokine release.

The standard of care for invasive mechanical ventilation in ARDS is a volumeand pressure-limited ventilation strategy, which improves survival, in large part through the minimization of ventilator-associated lung injury (VALI).

\section{ECMO}

ECMO stands for a circulatory and/or ventilatory assistance technique allowing respiratory or cardiac support while the underlying pathology is reversed or resolved. There are two main types of ECMO: venous (VV) and venous arterial (VA), they each have precise indications, advantages but also common and specific complications.

It requires a specific and specialized environment with trained staff capable of managing its associated difficulties and possible complications.

\section{Physiology}

ECMO refers to a circuit that directly oxygenates and removes carbon dioxide from blood through an extracorporeal gas exchange device, commonly referred to as a membrane oxygenator. The oxygenator consists of a semipermeable membrane that separates a blood compartment from a gas compartment, allowing only gas molecules to diffuse between compartments.

At the time of ECMO initiation, catheters (or cannulas) are placed in central vessels. Deoxygenated blood is drained from the body by an external pump, after which it passes through the membrane oxygenator and is reinfused back into the patient. When the drainage and reinfusion cannulas are both located in central veins, the circuit is referred to as venovenous ECMO, and the device provides gas exchange support only. When blood is drained from a vein and reinfused into an artery, it is referred to as venoarterial ECMO, and the circuit provides both gas exchange and circulatory support [4].

Typically, venovenous ECMO is used for respiratory failure such as ARDS whereas veno-arterial ECMO is indicated in cases with respiratory and hemo- 
dynamic instability.

\section{Indications for Venovenous ECMO}

The most common indication for ECMO in respiratory failure is severe ARDS. It is also the only indication with a high level of evidence through randomized controlled studies. Other potential indications based only on cohort studies include: acute hypercapnic respiratory failure, a bridge to lung transplantation or as a primary graft dysfunction after lung transplantation, or in case of pulmonary hypertension with right ventricular failure [4].

In all cases, ECMO is considered as a temporary solution biding for recovery of the underlying condition or for a lung transplant [5].

\section{Contraindications}

Relative contraindications to ECMO in acute respiratory failure include the prolonged use of high-pressure ventilation or high $\mathrm{FIO}_{2}$, limited vascular access, contraindications to the use of anticoagulation, and the presence of any condition or organ dysfunction that would limit the likelihood of overall benefit from ECMO (eg, severe irreversible brain injury or untreatable metastatic cancer). An absolute contraindication to ECMO is the presence of severe irreversible respiratory failure if transplantation will not be considered.

The assessment process can be based on progonostic scoring systems that help risk stratify patients being considered for ECMO in respiratory failure [6].

The decision to implant ECMO requires careful assessment of the risk-benefit balance. The contraindications must be respected insofar as these patients can no longer live without ECMO with a highly improbable recovery and are not candidates for definitive therapy, which constitutes for a real ethical dilemma [7].

\section{Complications}

ECMO is an invasive therapy associated with multiple complications, ranging from hemorrhage to thromboembolic events and an increased risk of infection [8] [9]. This implies the need for continuous systemic anticoagulation to maintain ECMO circuit patency and minimize the risk of thrombosis in both the circuit and the patient; this requires a strict balance control of both thrombotic risk and the potential hemorrhagic complications [10].

Hematological disorders are also very commonly associated to ECMO practice, including hemolysis, thrombocytopenia, acquired Von Willebrand syndrome and disseminated intravascular coagulopathy [4] [11].

\section{Evidence for ECMO Use as a Treatment Line in ARDS}

ECMO has been developed as a second line management therapy for severe ARDS cases, and has recently been the object of randomized controlled trials to establish its efficacy and safety. 
Many Cohort series demonstrated a high survival rate in patients with severe ARDS using ECMO and pressure-supported ventilation with minimal sedation [12] [13].

The results of the EOLIA trial were published in 2018 involving patients with very severe forms of ARDS defined by a $\mathrm{PaO}_{2} / \mathrm{FiO}_{2}$ ratio of less than $50 \mathrm{mmHg}$ for more than 3 hours or less than $80 \mathrm{mmHg}$ for more than 6 hours or respiratory acidosis with a $\mathrm{pH}<7.25$ and a $\mathrm{paCO}_{2}>60 \mathrm{mmhg}$ for more than 6 hours. Patients were randomized to receive either conventional treatment (control group) or immediate venous-venous ECMO. Cross-over to ECMO was possible for patients in the control group who had refractory hypoxemia. The primary endpoint was 60-day mortality.

Among the very severe ARDS patients in the EOLIA study, the 60-day mortality was not significantly lower with the use of ECMO as a rescue treatment compared to a conventional ventilatory strategy. In addition, the rate of hemorrhagic or ischemic complications was similar between the two groups [14].

However, a post-hoc Bayesian analysis of the EOLIA data showed a high likelihood of survival benefit with ECMO under a broad set of assumptions [15].

A recently published meta-analysis suggests that the use of venovenous ECMO in adults with severe acute respiratory distress syndrome was associated with reduced 60-day mortality compared with conventional mechanical ventilation. However, venovenous ECMO was also associated with a moderate risk of major bleeding [16].

The role of ECMO in the most severe forms of ARDS is evolving. It is not a substitute for lung-protective ventilation and adherence to other proven strategies, when such strategies are available and applied appropriately. Likewise, the use of algorithm based treatments and selection of patients suitable for ECMO therapy is a must as it should not be considered as a first-line therapy for ARDS rather than a justified decision under specific circumstances when the current standard of care is insufficient to support the patient [17].

\section{Prognosis}

Few large scale studies have evaluated long term quality recovery of survival patients after severe ARDS who benefited from ECMO assistance. A follow-up program including twenty-one long term survivors showed that the majority of patients had good physical and social functioning but a reduced health related quality of life according to the St George's Respiratory Questionnaire (SGRQ). Lung parenchymal changes on high-resolution computed tomography were suggestive of fibrosis and minor pulmonary function abnormalities remained common and can be detected more than 1 year after ECMO [18].

\section{Conclusion}

ECMO is an assistance technique capable of supporting severe hematosis disorders in acute respiratory failure, with data showing potential benefits for im- 
proving survival in patients with severe ARDS. Its use should remain in centers sufficiently experienced with the procedure in specific indications as additional research is needed before ECMO can be recommended for more extensive practice.

\section{Funding Source}

This research did not receive any specific grant from funding agencies in the public, commercial, or not-for-profit sectors.

\section{Conflicts of Interest}

The authors declare no conflicts of interest regarding the publication of this paper.

\section{References}

[1] Bellani, G., Laffey, J.G., Pham, T., Fan, E., Brochard, L., Esteban, A., et al. (2016) Epidemiology, Patterns of Care, and Mortality for Patients with Acute Respiratory Distress Syndrome in Intensive Care Units in 50 Countries. The Journal of the American Medical Association, 315, 788-800. https://doi.org/10.1001/jama.2016.0291

[2] Brodie, D. and Bacchetta, M. (2011) Extracorporeal Membrane Oxygenation for ARDS in Adults. The New England Journal of Medicine, 365, 1905-1914. https://doi.org/10.1056/NEJMct1103720

[3] Ranieri, V.M., Rubenfeld, G.D., Thompson, B.T., Ferguson, N.D., Caldwell, E., et al. (2012) ARDS Definition Task Force, Acute Respiratory Distress Syndrome: The Berlin Definition. The Journal of the American Medical Association, 307, 2526-2533.

[4] Abrams, D. and Brodie, D. (2017) Extracorporeal Membrane Oxygenation for Adult Respiratory Failure: 2017 Update. Chest, 152, 639-649. https://doi.org/10.1016/j.chest.2017.06.016

[5] Richard, C., Argaud, L., Blet, A., Boulain, T., Contentin, L., et al. (2014) Extracorporeal Life Support for Patients with Acute Respiratory Distress Syndrome: Report of a Consensus Conference. Annals of Intensive Care, 4, 15. https://www.ncbi.nlm.nih.gov/pmc/articles/PMC4046033/

[6] Schmidt, M., Zogheib, E., Rozé, H., Repesse, X., Lebreton, G., Luyt, C.-E., et al. (2013) The Preserve Mortality Risk Score and Analysis of Long-Term Outcomes after Extracorporeal Membrane Oxygenation for Severe Acute Respiratory Distress Syndrome. Intensive Care Medicine, 39, 1704-1713. https://doi.org/10.1007/s00134-013-3037-2

[7] Mosier, J.M., Kelsey, M., Raz, Y., Gunnerson, K.J., Meyer, R., Hypes, C.D., Malo, J., Whitmore, S.P. and Spaite, D.W. (2015) Extracorporeal Membrane Oxygenation (ECMO) for Critically Ill Adults in the Emergency Department: History, Current Applications, and Future Directions. Crit Care, 19, 431. https://pubmed.ncbi.nlm.nih.gov/26672979/

[8] Schmidt, M., Bréchot, N., Hariri, S., Guiguet, M., Luyt, C.E., Makri, R., et al. (2012) Nosocomial Infections in Adult Cardiogenic Shock Patients Supported by Venoarterial Extracorporeal Membrane Oxygenation. Clinical Infectious Diseases, 55, 1633-1641. https://doi.org/10.1093/cid/cis783

[9] Paden, M.L., Rycus, P.T. and Thiagarajan, R.R. (2014) Update and Outcomes in 
Extracorporeal Life Support. Seminars in Perinatology, 38, 65-70. https://doi.org/10.1053/j.semperi.2013.11.002

[10] Eric, S., Sklar, M.C., Lequier, L., Fan, E. and Kanji, H.D. (2017) Anticoagulation Practices and the Prevalence of Major Bleeding, Thromboembolic Events, and Mortality in Venoarterial Extracorporeal Membrane Oxygenation: A Systematic Review and Meta-Analysis. Journal of Critical Care, 39, 87-96.

https://doi.org/10.1016/j.jcrc.2017.02.014

[11] Abrams, D., Baldwin, M.R., Champion, M., Agerstrand, C., Eisenberger, A., Bacchetta, M. and Brodie, D. (2016) Thrombocytopenia and Extracorporeal Membrane Oxygenation in Adults with Acute Respiratory Failure: A Cohort Study. Intensive Care Medicine, 42, 844-852. https://doi.org/10.1007/s00134-016-4312-9

[12] Lindén, V., Palmér, K., Reinhard, J., Westman, R., Ehrén, H., Granholm, T. and Frenckner, B. (2000) High Survival in Adult Patients with Acute Respiratory Distress Syndrome Treated by Extracorporeal Membrane Oxygenation, Minimal Sedation, and Pressure Supported Ventilation. Intensive Care Medicine, 26, 1630-1637. https://doi.org/10.1007/s001340000697

[13] Peek, G.J., Moore, H.M., Moore, N., Sosnowski, A.W. and Firmin, R.K. (1997) Extracorporeal Membrane Oxygenation for Adult Respiratory Failure. Chest, 112, 759-764. https://doi.org/10.1378/chest.112.3.759

[14] Combes, A., Hajage, D., Capellier, G., Demoule, A., Lavoué, S., Guervilly, C., et al. (2018) Extracorporeal Membrane Oxygenation for Severe Acute Respiratory Distress Syndrome. The New England Journal of Medicine, 378, 1965-1975. https://doi.org/10.1056/NEJMoa1800385

[15] Goligher, E.C., Tomlinson, G., Hajage, D., Wijeysundera, D.N., Fan, E., Jüni, P., et al. (2018) Extracorporeal Membrane Oxygenation for Severe Acute Respiratory Distress Syndrome and Posterior Probability of Mortality Benefit in a Post Hoc Bayesian Analysis of a Randomized Clinical Trial. The Journal of the American Medical Association, 320, 2251-2259. https://doi.org/10.1001/jama.2018.14276

[16] Munshi, L., Walkey, A., Goligher, E., Pham, T., Uleryk, E.M. and Fan, E. (2019) Venovenous Extracorporeal Membrane Oxygenation for Acute Respiratory Distress Syndrome: A Systematic Review and Meta-Analysis. The Lancet Respiratory Medicine, 7, 163-172. https://doi.org/10.1016/S2213-2600(18)30452-1

[17] Abrams, D. and Brodie, D. (2017) Extracorporeal Membrane Oxygenation Is First-Line Therapy for Acute Respiratory Distress Syndrome. Critical Care Medicine, 45, 2070-2073. https://doi.org/10.1097/CCM.0000000000002734

[18] Lindén, V.B., Lidegran, M.K., Frisén, G., Dahlgren, P., Frenckner, B.P. and Larsen, F. (2009) ECMO in ARDS: A Long-Term Follow-Up Study Regarding Pulmonary Morphology and Function and Health-Related Quality of Life. Acta Anaesthesiologica Scandinavica, 53, 489-495. https://doi.org/10.1111/j.1399-6576.2008.01808.x 